\title{
THE CARDIOVASCULAR AND METABOLIC RESPONSES TO WATER AEROBICS EXERCISE IN MIDDLE-AGED AND OLDER ADULTS
}

\author{
Amy L. Nikolai, Brittany A. Novotny, Cortney L. Bohnen, Kathryn M. Schleis, Lance C. Dalleck, PhD \\ University of Wisconsin - Eau Claire, Eau Claire, WI
}

\section{Abstract}

Background: The purpose of this study was (a) to assess the cardiovascular and metabolic responses to water aerobic exercise and (b) to determine if water aerobics exercise meets the American College of Sports Medicine (ACSM) guidelines for
improving and maintaining cardiorespiratory fitness. Methods: Fourteen men and women (mean $\pm \mathrm{SD}$ age, height, weight, body fat percentage, and maximal oxygen $31.0 \pm 8.3 \mathrm{~mL} / \mathrm{kg} / \mathrm{min}$, respectively) completed a maximal treadmill exercise test and 50 min water aerobics session. Cardiovascular and metabolic data were collected via a

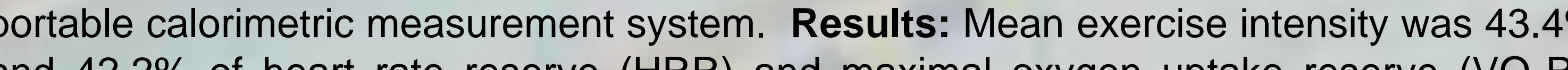
respectively. Training intensity in metabolic equivalents (METS) was $4.26 \pm 0.96$. Total net energy expenditure for the exercise session was $249.1 \pm 94.5 \mathrm{kcal} / \mathrm{session}$
Conclusions: Results indicate that water aerobics is a feasible alternative to land-based Conclusions: Results indicate that water aerobics is a feasible alternative to land-based exercise for middle-aged and older aduls
and maintaining cardiorespiratory fitness.

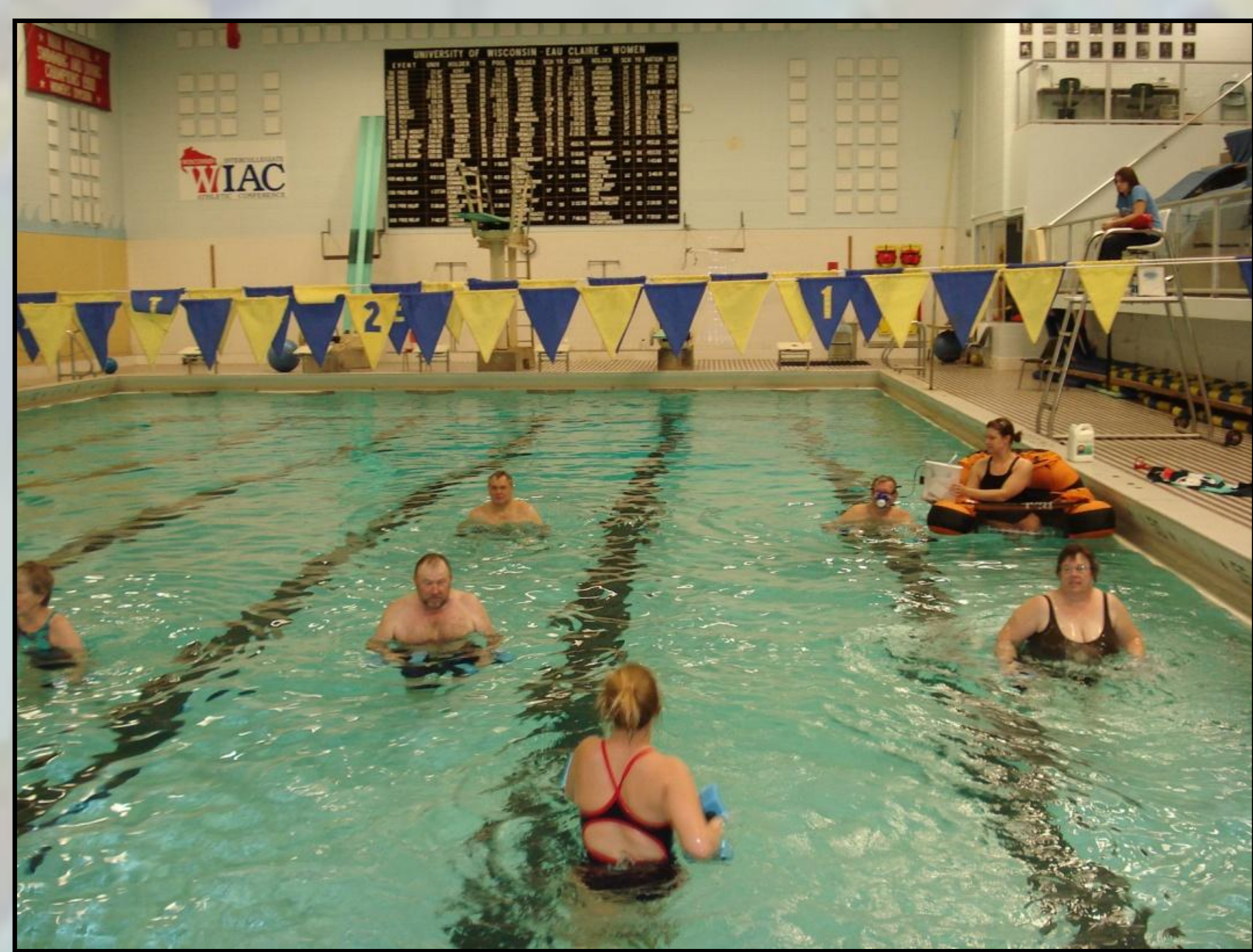

\section{Introduction}

It is known that regular physical activity confers numerous health benefits, such as the prevention and control of hypertension, obesity, diabetes, dyslipidemia, and coronary artery disease. It has been suggested by Franklin (2007) that the most important benefit is the increase in cardiorespiratory fitness, as it is perhaps the best marker for risk stratification and health outcomes. To produce the benefits of cardiorespiratory fitness the American College of Sports Medicine (ACSM) currently recommends 2060 minutes of aerobic exercise 3-5 days/week at an intensity of $64 / 70-94 \%$ of heart rate maximum (HRmax), 40/50-85\% of heart rate reserve (HRR) or oxygen uptake reserve $\left(\mathrm{VO}_{2} \mathrm{R}\right)$, and 12-16 rating of perceived exertion (RPE). Additionally, the ACSM has recommended a target energy expenditure of 150 to 400 net kilocalories per day (kcal/day). Due to the potential high impact demands of traditional land-based exercise, such as walking or jogging, these guidelines may be difficult to attain for those individuals with limiting physical conditions, such as low back pain or osteoarthritis. For this reason aquatic exercise and water aerobics have become an increasingly popular, alternative form of aerobic exercise for those who are physically limited, injured and/or older.

\section{Purpose}

The purpose of this study was (a) to assess the cardiovascular and metabolic responses to water aerobic exercise and (b) to determine if water aerobics exercise meets the ACSM guidelines for improving and maintaining cardiorespiratory fitness. It was hypothesized that water aerobics will meet the recommended guidelines for moderate intensity exercise as stated by the ACSM.

\section{Methods}

Fourteen subjects participated in two separate testing sessions consisting of a maximal exercise test and a water aerobics exercise session. Subject characteristics are presented in Table 1 . All cardiovascular and metabolic data were measured using a CosMed K4 b2 (Rome, Italy) portable calorimetric measurement system.

Table 1. Subject Characteristics

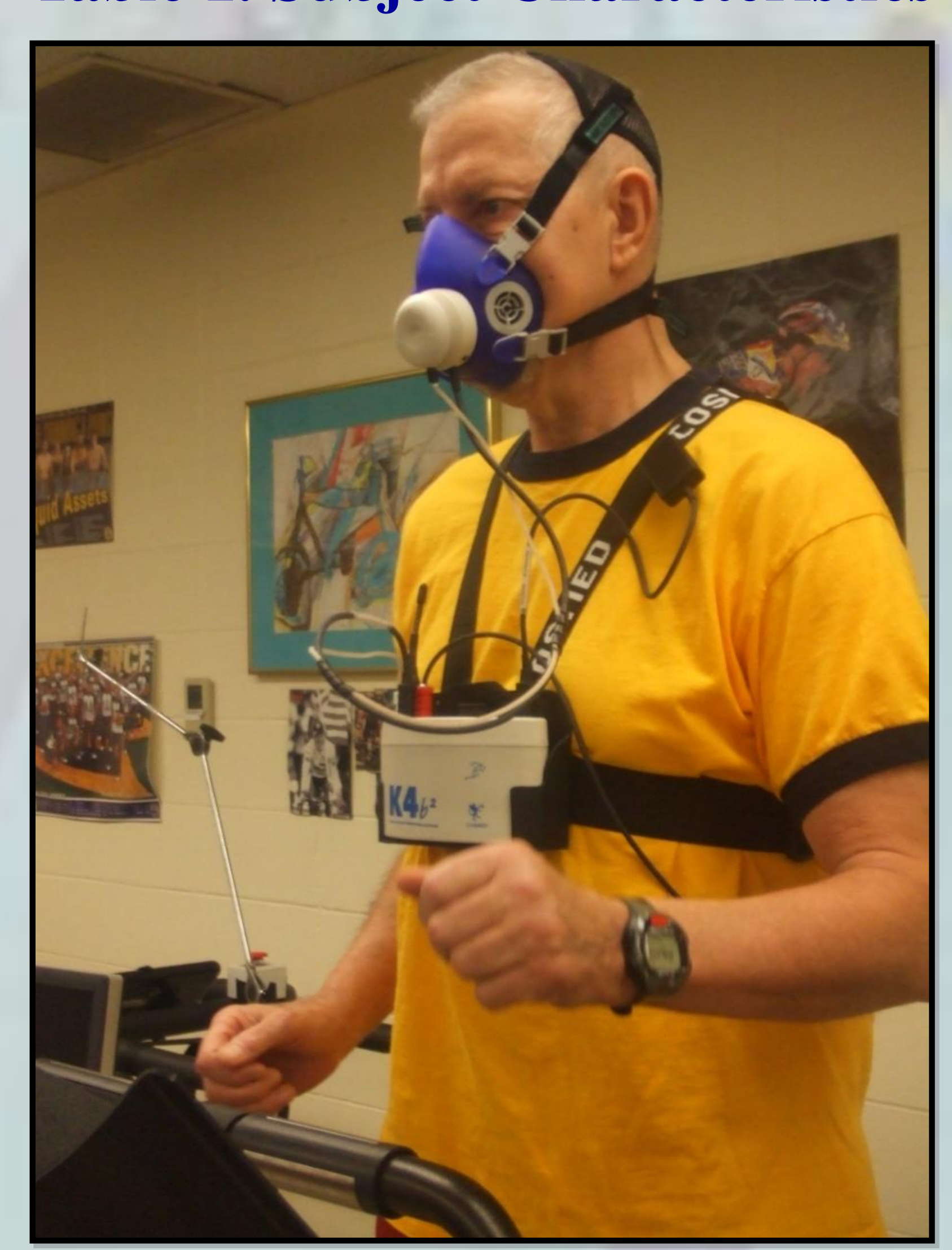

\begin{tabular}{ccccccc} 
& $\begin{array}{c}\text { Age } \\
(\mathbf{y r})\end{array}$ & $\begin{array}{c}\text { Height } \\
(\mathbf{c m})\end{array}$ & $\begin{array}{c}\text { Fat } \\
(\%)\end{array}$ & $\begin{array}{c}\text { Weight } \\
(\mathbf{k g})\end{array}$ & $\begin{array}{c}\text { HR Max } \\
\left(\text { (beat }_{\mathbf{~ m i n}}{ }^{-1}\right)\end{array}$ & $\begin{array}{c}\mathbf{V O}_{2} \mathbf{m a x} \\
\left(\mathbf{m L}^{-1} \cdot \mathbf{k g}^{-1} \cdot \mathbf{m i n}^{-1}\right)\end{array}$ \\
\hline Mean & 57.4 & 171.3 & 32.5 & 89.9 & 160.4 & 31.0 \\
SD & 7.6 & 7.8 & 5.8 & 13.9 & 23.4 & 8.3 \\
\hline
\end{tabular}

\section{Results}

Relative percent $\mathrm{HRR}$ and $\mathrm{VO}_{2} \mathrm{R}$ ranged from $19 \%$ to $68 \%$ and $25 \%$ to $63 \%$, respectively during water aerobic exercise. Intensity expressed as MET values ranged from 3.0 to 5.8, while total net energy expenditure ranged from 115.0 to $418.0 \mathrm{kcal} / \mathrm{session}$. Cardiovascular and metabolic responses (mean $\pm \mathrm{SD}$ ) to the water aerobic exercise session are presented in Table 2.

Table 2. Cardiovascular and Metabolic Responses to Water Aerobics

\begin{tabular}{cccc}
\hline Parameter & $\begin{array}{c}\text { Women } \\
(\mathbf{N}=7)\end{array}$ & $\begin{array}{c}\text { Men } \\
(\mathbf{N}=7)\end{array}$ & $\begin{array}{c}\text { Combined } \\
(\mathbf{N}=\mathbf{1 4})\end{array}$ \\
\hline HR (beats min $\left.^{-1}\right)$ & $111.0 \pm 15.3$ & $104.7 \pm 13.5$ & $107.8 \pm 14.2$ \\
\% HRR & $37.9 \pm 9.2$ & $48.8 \pm 12.8$ & $43.4 \pm 12.1$ \\
$\begin{array}{c}\text { Metabolic equivalents } \\
(\mathrm{METs})\end{array}$ & $3.99 \pm 0.96$ & $4.53 \pm 0.96$ & $4.26 \pm 0.96$ \\
\% $\mathrm{VO}_{2} \mathrm{R}$ & $38.4 \pm 7.3$ & $46.0 \pm 11.2$ & $42.2 \pm 9.9$
\end{tabular}

Energy Cost $\left(\mathrm{kcal} \cdot \mathrm{session}^{-1}\right) \quad 220.7 \pm 83.1 \quad 277.4 \pm 102.8 \quad 249.1 \pm 94.5$

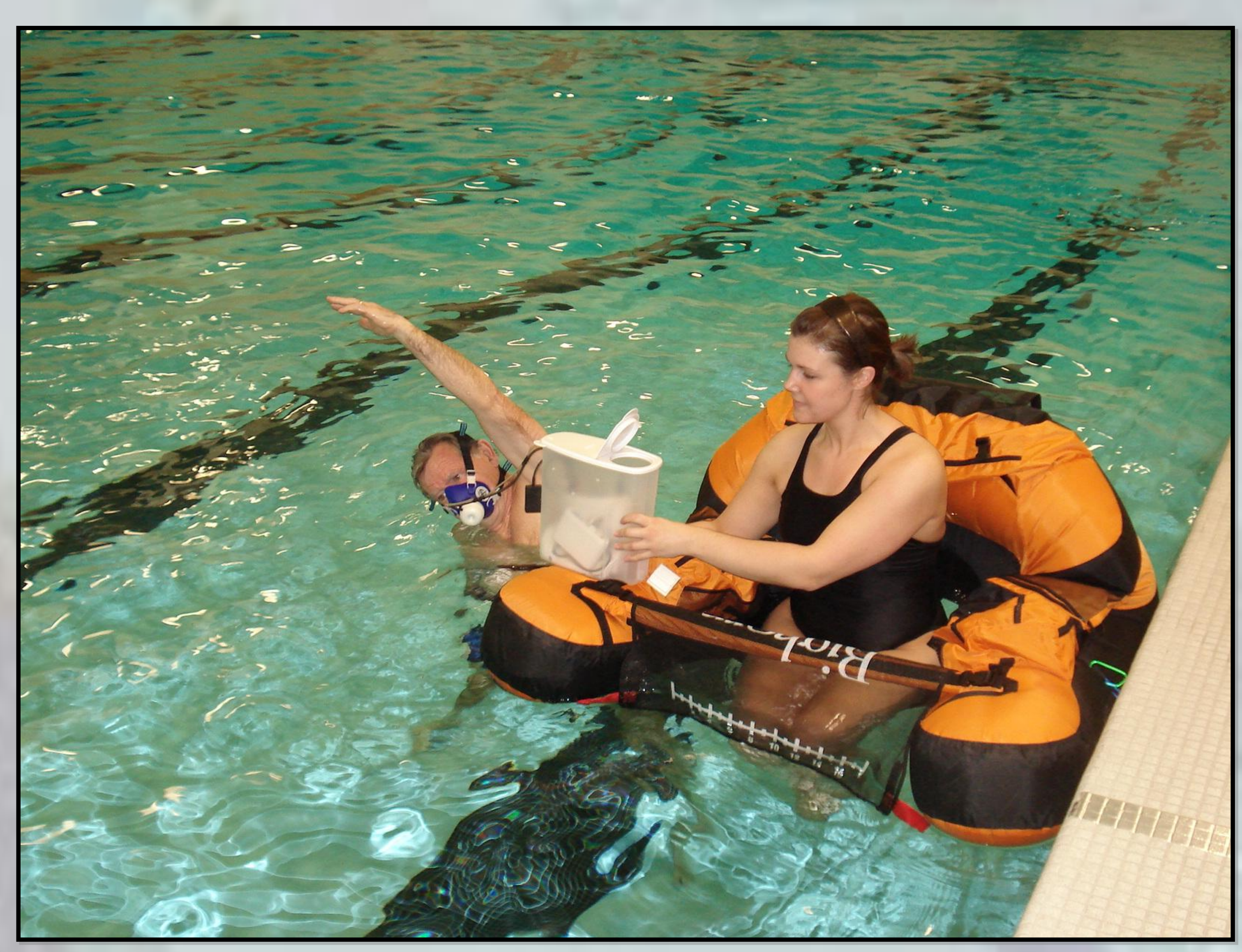

Summary and Conclusions

Findings from the present study support water aerobics as a feasible alternative to land-based exercise for older adults.

Importantly, participation in water aerobics fulfills the ACSM energy expenditure (>150 kcal/day) and exercise intensity (>40\% HRR or $\mathrm{VO}_{2} \mathrm{R}$ ) guidelines for improving and maintaining cardiorespiratory fitness.

The MET values elicited by water aerobics are comparable to traditional land-based exercises such as treadmill walking at $5 \mathrm{~km} / \mathrm{h}$ which is equivalent to 3.3 METs, and cycling between 50-100 Watts which elicits a MET value ranging between 4 and 6 METs.

$>$ The results are significant for middle-aged to older adults, as low cardiorespiratory fitness may contribute to premature mortality.

Decreased cardiorespiratory fitness is also associated with a reduction in physiological functional capacity, which can ultimately lead to a loss of independence for older populations.

Findings are important for fitness instructors, physical therapists, and others who design exercise programs for adult populations with the ultimate goal of increasing or maintaining cardiorespiratory fitness.

\section{References}

1. AMERICAN COLLEGE OF SPORTS MEDICINE. ACSM's Guidelines for Exercise Testing and Prescription (7th ed.). Baltimore, MD: Lippincott Williams \& Wilkins, 2006. pp. 10, 141-149.

U.S. DEPARTMENT OF HEALTH AND HUMAN SERVCES. Surgeon General's repor Physical activity and health. Washington, DC: U.S. Department of Health and Huma Services; 1996

FRANKLIN B A. Fitness: The Ultimate Marker for Risk Stratification and Health Outcomes? Preventive Cardiology Winter 2007 p. 42-45.

\section{Acknowledgements}

We would like to thank our enthusiastic participants and the water aerobics instructor for 